The Preparation of Educational Psychologists in Hong Kong

Shui-fong Lam

The University of Hong Kong

Shui-fong Lam

Department of Psychology

University of Hong Kong

Pokfulam Road

Hong Kong, China

E-mail: lamsf@hku.hk.

Telephone: (852) 3917-2388.

Fax: (852) 2858-3518 


\begin{abstract}
Modeled after the British system, school psychologists in Hong Kong are called educational psychologists. Hong Kong is the first location in Asia to have a recognized specialty vocation in educational psychology and a program for their professional preparation. The first program in Hong Kong, established by the University of Hong Kong in 1981 during the British colonial rule, is a two-year full-time master’s degree program that adopts a scholar-practitioner model. Three more programs have been developed in Hong Kong during the last decade. The Hong Kong Polytechnic University established a master’s degree program in 2009. The University of Hong Kong also launched a doctor of philosophy program and a doctor of psychology program in educational psychology at about the same time. The rapid growth in quantity and quality of professional preparation in Hong Kong is a response to the local expansion of the educational psychology services as well as regional and global trend in professional preparation. The purpose of this article is to describe the preparation of educational psychologists in Hong Kong, the nature of their services, and the impact of living and working in a multicultural environment on them.
\end{abstract}

Keywords: educational psychologist, professional education, Hong Kong 


\section{The Preparation of Educational Psychologists in Hong Kong}

\section{Social, Cultural and Educational Contexts}

Hong Kong has been a special administration region of China since 1997 when the United Kingdom relinquished its sovereignty to China. As a special administration region, Hong Kong has its own legal system, currency, customs, immigration authorities, and its own way of life, shaped during the 155 years of British colonization. Although the colonization has carved many Western features into Hong Kong’s social, economic, legal, and political landscape, Hong Kong has preserved many aspects of Chinese culture. It is a melting pot of the traditional and the modern, the Oriental and the Occidental.

Hong Kong’s economy is characterized by its high degree of internationalization, well-established financial networks, and free trade. In 2011, the population of its labor force was 3.58 million, with the majority engaged in wholesale, retail, import/export trades, finance, insurance, and business services (Census and Statistics Department, 2012a). In 2012, Hong Kong’s gross domestic product was US\$261.6 billion and its per capita gross domestic product was US\$36,557. The median household annual income was US\$31,846 (Census and Statistics Department, 2013). Although Hong Kong is an affluent society, problems associated with income inequality are alarming. For example, in 2011, Hong Kong scored 53.7 on the Gini Scale ${ }^{1}$ (Central Intelligence Agency, 2013). Many local educators are concerned about the impact of economic polarization on the education opportunities of children in poverty (“Gap between the Rich,” 2013).

Hong Kong is a densely populated city, with 7.16 million people living in a landmass of 1,103 square kilometers. Its population is homogeneous with $94.6 \%$ Chinese

\footnotetext{
${ }^{1}$ Gini coefficient is a measure of income inequality. It ranges from 0 to 100 . A society that scores 0 on the Gini scale has perfect equality in income distribution. Higher the number indicates higher the inequality. Most developed European countries have Gini coefficients between 24 and 36
} 
and 5.4\% ethnic minorities. Most of the latter are Indonesians, Filipinos, and South Asians (Census and Statistics Department, 2012b). Despite its relatively small percent of population, concern for their educational needs is increasing (Liu, 2013).

During the last decade, another new development also has attracted the attention from educators: Many mothers from mainland China come to Hong Kong to deliver their babies. In 2011, 37\% of the infants born in Hong Kong were offspring of mainland Chinese (“Mainland Babies,” 2012). These children have the right to access a free and universal basic education in Hong Kong. In 2012, about 17,000 students from mainland China crossed the border on daily basis to attend schools in Hong Kong. The adjustment of these young commuters is a concern for educators (International Social Services, 2012).

In 2011, the number of children and teenagers (defined as aged 19 or younger) in Hong Kong was 1.25 million and comprise 17.5\% of Hong Kong’s population (Census and Statistics Department, 2012a). During the 2012/13 fiscal year, the Hong Kong government spent $20.4 \%$ of its total public expenditure, an equivalent of $3.8 \%$ of Hong Kong's gross domestic product, on education. Hong Kong has 166,400 kindergarteners (ages 3-5), 320,700 primary students (ages 6-11), and 439,100 secondary students (ages 12-18) enrolled in 957 kindergartens, 569 primary schools, and 519 secondary schools, respectively (Education Bureau, 2013). Since September 2010, Hong Kong provides 12 years of free and universal basic education to students from grades 1 through 12 . The public is requesting preschool education be added to the free and universal basic education. The government responded recently by establishing a committee to consider this request (Information Services Department, 2013). 
Inclusive education for special needs children was launched in 1997 when the government implemented a pilot project, the Whole School Approach to Integration. Currently, 31,390 students with special educational needs enrolled in regular primary and secondary schools in Hong Kong. They make up 5\% of the student population. Although it is the government's policy to mainstream children with special needs wherever possible, Hong Kong still has 7,946 students enrolled in 61 special schools because of the severity of their disabilities (Education Bureau, 2013).

The development of educational psychology services in Hong Kong is closely related to special education services. First introduced in 1959 when the government established a special education section, the services can be considered as one of Britain's legacies to Hong Kong. Hong Kong is the first Asia location with a recognized specialty profession in educational psychology and a postgraduate program for their professional preparation.

\section{Program Demographics}

The University of Hong Kong established its professional education program in 1981, one modeled after the then British system. Thus, it first offered a one-year full-time master’s program that required applicants to possess teaching qualification and a bachelor's degree in psychology. Two years later, the program was extended to two years in view of the inadequacy of one-year preparation and the high expectations of competency for educational psychologists. In between 1981 and 2013, 161 students had graduated from this program. Most (86\%) are female, in their mid or late 20s, and had two or three years of work experience as teachers or guidance personnel in educational settings before being admitted. A bachelor's degree in psychology remains an admission 
requirement and the teaching qualification and experience now are considered preferable assets.

In 2009, a second professional education program was set up by the Hong Kong Polytechnic University. Its establishment was a response to the rapid expansion of services and serious shortage of educational psychologists after the government decided to launch school-based services in primary schools in 2005. To deal with this unprecedented service expansion, the program at the University of Hong Kong also increased its admission quota. At present, the program at the University of Hong Kong admits 25 students every even year whereas the program at Hong Kong Polytechnic University admits 15 students every odd year. These two programs are very similar because both must meet the training standards specified by the professional body of educational psychology in Hong Kong (Division of Educational Psychology, 2008). Both are two-year full-time master's programs with the majority of students being females. Since its inception in 2009, the program at the Hong Kong Polytechnic University has provided professional preparation to 30 students, in which only six were male students.

As of 2013, the program at the University of Hong Kong comprises five full-time faculty members, in which three are female and two are male. All of them hold a doctoral degree. The program at the Hong Kong Polytechnic University comprises three full-time faculty members. All are females, two hold a doctoral degree, and one holds a master's degree. Both programs have four to five part-time teachers who liaise with the on-site supervisors to oversee students' practical work or provide direct supervision to students working in the in-house clinic on campus. These part-time teachers are senior educational 
psychologists who work as practitioners. All hold a master’s degree or higher qualification.

The basic qualification of an educational psychologist in Hong Kong is a master's degree. However, there is a strong demand for educational psychologists who have qualifications beyond master's level. To advance the local services, there is a need for educational psychologists with a specialization at doctoral level. Internationally, there is also a trend to upgrade the professional preparation for educational psychologists. In 2006, England has changed all post-graduate programs in educational psychology to three-year professional doctorates (Division of Educational and Child Psychology, 2006). In view of the local demand and global trend, the University of Hong Kong founded a Doctor of Psychology (PsyD) program in 2008. Applicants to this program must be educational psychologists who have acquired a master's degree in educational psychology. It is a three-year part-time program for the experienced educational psychologists who aspire to further develop their expertise. Since 2008, five experienced educational psychologists had graduated from this program. Currently, this program has five students. Among all the past and present PsyD students, only one is male.

In addition to its PsyD program, in 2007 the University of Hong Kong also launched a four-year full time doctor of philosophy $(\mathrm{PhD})$ program in educational psychology that has a more vigorous research component. Unlike the PsyD program, this PhD program accepts students who do not have a master's degree in educational psychology. During the first two years these PhD students take all courses with those in the master's program and then remain for two more years to complete their $\mathrm{PhD}$ theses. 
As of September 2013, two students have graduated and six currently are enrolled. Among all the past and present $\mathrm{PhD}$ students, only two are males.

In summary, Hong Kong has four programs for the preparation of educational psychologists: two at master’s level and two at doctoral level. Despite the variety, the master's program at the University of Hong Kong is the prototype of all the other three programs. While the two master's programs are very similar, the two doctoral programs are developed on top of the master's program at the University of Hong Kong. To present a concise account about the preparation of educational psychologists in Hong Kong, the current article focuses on the master's program at the University of Hong Kong and describes it in details.

\section{The Master Program in Educational Psychology at the University of Hong Kong}

\section{Program Statement}

The aim of this program is to provide professional preparation to educational psychologists who can function as scholar-practitioners. It places great emphasis on the synthesis between research and practice. This emphasis arises from how the program defines educational psychologists:

Educational psychologists are expected to apply broad-based knowledge of psychology to educational settings. They are scholars who generate scientific knowledge and theory relevant to education and psychology. They are also practitioners whose services range from remediation to prevention, case work to systems work, and direct services (University of Hong Kong, Department of Psychology, 2012, p. 1). 
On basis of the above conceptualization, this program places strong emphasis on synthesis between research and practice. It also adopts a proactive and systems orientation that is in line with the service delivery model that addresses all levels of intervention. The program consists of three basic components designed to prepare educational psychologists who can function competently as scholar-practitioners: academic courses, practicum, and research.

\section{Academic Courses}

During the two-year program, the students are required to take 14 academic courses. In their first year they take nine courses: psychoeducational assessment I and II; children with special needs I and II; psychoeducational intervention I and II; research methods and statistics I and II; and skills training seminar I. In their second year they take five courses: curriculum and instruction; motivation and learning; applied developmental psychology; professionalism, ethics and issues in educational psychology; and skills training seminar II.

\section{Practicum}

The students are required to engage in a minimum of 180 days of practicum during their two years of full-time study. Each student is placed in four different placement settings: 1) Education Bureau, 2) special schools or centers, 3) regular schools, and 4) Psychological Services Unit of the Department of Psychology at the University of Hong Kong. The first three settings are outside the university whereas the last setting is an in-house clinic on campus. The on-site supervisors are educational psychologists with at least a master's degree and a minimum of 3 years of experience.

\section{Research}


The students are required to conduct an empirical study in educational psychology. Although the master's level program is two-year program, the students are able to engage in edge-cutting research under the supervision of the program staff. That many theses have been published in peer-reviewed journals (e.g., Keung \& Ho, 2009, S.f. Lam \& Lau, 2008; S.-f. Lam, Cheng, \& Choy, 2010; S.-f. Lam, Yim, \& Ng, 2008; T. W. H. Lam \& Chiu, 2002; Leung \& Lam, 2003) speaks to the fact that the research component in the professional preparation is strong.

\section{Multicultural and International emphasis}

Hong Kong is a Chinese society but English is the teaching medium at the University of Hong Kong. Situated in a metropolis where East meets West, the master’s program at the University of Hong Kong has at least three challenges regarding multicultural and international issues. First, it has to draw upon the rich literature and experience from the West in the students’ academic preparation. Therefore, the program adopts many textbooks from the U.S. (e.g., Thomas \& Grimes, 2008) and regularly sends some of its students for overseas attachment (Keung \& Chan, 2005, September). Second, the program strives to develop local literature and practices so that the knowledge and practices of the students are not awkward transplants from the West that do not fit the Chinese context. Therefore, the program staff are engaged actively in research so as to develop culturally sensitive knowledge and practices (e.g., Ho, Leung, \& Cheung, 2011; S.-f. Lam, Wong, Leung, Ho, \& Au-Yeung, 2010). Third, the educational needs of nonChinese ethnic minorities are an increasing concern (Liu, 2013), thus prompting the need for the program to prepare students with the ability to work with people from different ethnic backgrounds. 
The program faculty obtained their degrees from Australia, Canada, England, United States, as well as Hong Kong. Their diverse backgrounds contribute to the international emphasis of the program. To keep abreast of international development of the profession and services in educational psychology, they have close ties with the international community. For example, the program director remains actively engaged with the International School Psychology Association (ISPA), is a member of the ISPA Task Force on Accreditation, and is on the executive committee of the International Institute of School Psychology. She also coordinates a multi-national research project on school engagement (S.-f. Lam et al, 2012).

\section{Professional Involvement}

Maintaining close connection with the local community is also important to the program. Most program faculty serve as honorary consultants in nongovernment organizations that provide educational psychology services in Hong Kong. Four of its faculty have chaired the professional body of educational psychology in Hong Kongone founded by the first program director in 1987. Since its establishment, the program faculty have assumed a leadership role in this organization.

The program has also been actively involved in the development of educational psychology services in Hong Kong. In between 2002 to 2005, the program faculty directed a pioneer project that provided educational psychology services to 25 primary schools in order to persuade the Hong Kong government to extend educational psychology services to primary schools (Education Manpower Bureau, 2005). The success of this pioneer project motivated the government to infuse substantial resources to primary schools for educational psychology services. It heralded the rapid expansion 
of educational psychology services in Hong Kong since 2005 and the establishment of the second professional education program at the Hong Kong Polytechnic University in 2009.

\section{Program Strengths, Weaknesses, and Challenges}

The curricula of the master's program has covered the core knowledge and skills described by the ISPA guidelines for the preparation of school psychologists (Cunningham \& Oakland, 1998). Although it is only a two-year program, it adopts a scholar-practitioner model and its success in synthesizing research and practice is evidenced by the many publications of its faculty members and students. Their research contributes to the body of knowledge that informs educational psychology services in Hong Kong (e.g., Ho et al., 2011; S.-f. Lam, Chow-Yeung, Wong, Lau, \& Tse, 2013; Wong, Ho, Chung, Chan, Tsang, \& Lee, 2009).

The program has a close connection with both the local and international communities. Its faculty provide pro bono consultation to many nongovernmental organizations that provide educational psychology services. They also assume leadership in the profession and conduct pioneer work to promote the services in Hong Kong. Internationally, its faculty members are active members of the ISPA and multi-national research projects (e.g., S.-f. Lam et al., 2012).

Despite the above strengths, the program faces a number of weaknesses and impending challenges. In response to the unprecedented expansion of services, the program has drastically increased its admission quota from 13 in 2004 to 20 in 2006, and further to 25 in 2010. This rapid expansion has exerted considerable pressure on staffing. In addition, the large class size poses challenges to teaching and learning. Program 
enrollment is related closely to the demand for educational psychologists in the community. Thus, program size will continue to fluctuate in accord with the expansion or stagnation of government-supported educational psychology services. More than $95 \%$ of the educational psychologists in Hong Kong work in the government or public schools. As the number of private schools is small, government policy on educational psychology services has a pivotal impact on admission of students and employment of graduates. By the end of the 2016/17 school year, the government will have met its target to cover all public primary and secondary schools with school-based psychological services (Legislative Assembly, 2013). All public sector positions for educational psychologists will be filled if there is no further expansion of services. Thus, the admission quotas of the master's programs in both the University of Hong Kong and the Hong Kong Polytechnic University may need to be reduced.

The erratic fluctuation of admission quota and program size may be avoided if the government considers improving the ratio between educational psychologists and the schools they serve. Currently, an educational psychologist serves 6 to 10 schools (approximately 6,000 to 10,000 students). This ratio is far from satisfactory and there is a great room for improvement. The possible inclusion of preschool education into the free and universal basic education also may affect the expansion of services, especially if educational psychology services are extended to kindergartens. In view of this possible extension, the program has been strengthening its curricular and practical work in preschool education.

As discussed earlier, the program has three challenges regarding multicultural and international concerns. Beyond these challenges, the program also has more challenges 
related to the economic polarization and the turnover of Hong Kong's sovereignty to China. First, how to address the educational needs of children in poverty should be included in the program curricula. Second, the new development in education arising from the intimate interaction between Hong Kong and mainland China needs to be considered. For example, the influx of the children across the border from mainland China to Hong Kong schools requires the attention of educational psychologists. Their adjustment and needs should be on the agenda of educational psychology services.

As Hong Kong now is a part of China, educational psychologists in Hong Kong should refer not only to Hong Kong but also to China as a whole when they address national needs and priorities. Being the only city in China that has professional education programs for educational psychologists, Hong Kong may be able to contribute to the development of educational psychology in China. By 2013, the master's program has provided professional education to two students from mainland China. It is foreseeable that more prospective educational psychologists from mainland China will benefit from the professional education in Hong Kong. 


\section{References}

Census and Statistics Department. (2012a). Hong Kong annual digest of statistics (2012 ed.). Hong Kong: Government Printer. Retrieved from http://www.statistics.gov.hk/pub/B10100032012AN12B0100.pdf

Census and Statistics Department. (2012b). Hong Kong 2011 population census thematic report: Ethnic minorities. Hong Kong: Government Printer. Retrieved from http://www.census2011.gov.hk/pdf/EM.pdf

Census and Statistics Department. (2013). Hong Kong in figures (2013 ed.). Hong Kong: Government Printer. Retrieved from http://www.statistics.gov.hk/pub/B10100062013AN13E0100.pdf

Central Intelligence Agency. (2013). The world fact book: Country comparison on distribution of family income - Gini index. Retreived from https://www.cia.gov/library/publications/the-worldfactbook/rankorder/2172rank.html

Cunningham, J., \& Oakland, T. (1998). International School Psychology Association guidelines for the preparation of school psychologists. School Psychology International, 19, 19-30.

Division of Educational and Child Psychology. (2006). Update on the training of educational psychologists. Retrieved from http://decp.bps.org.uk/decp/news/updatetraining1.cfm Division of Educational Psychology. (2008). Standards for the training of professional educational psychologists in Hong Kong. Hong Kong: Author. Retrieved from http://www.dep.hkps.org.hk/training.php?language=eng 
Education Manpower Bureau (2005). School based educational psychology services in primary school (Reference No. EMB(EPSPS)/RP/35/1/1, Circular No.119/2005). Hong Kong: Author.

Education Bureau. (2013). Figures and statistics. Retrieved from http://www.edb.gov.hk/en/about-edb/publications-stat/figures/index.html

Gap between the rich and the poor in college admission rates has enlarged. (2013, February 1). Mingpao, p.A28.

Ho, C. S.-H., Leung, M.-T., \& Cheung, H. (2011). Early difficulties of Chinese preschoolers at familial risk for dyslexia: Deficits in oral language, phonological processing skills, and print-related skills. Dyslexia, 17, 143-167.

Information Services Department. (2013, April 8). Press release: Appointments to committee on free kindergarten education. Retrieved from http://www.info.gov.hk/gia/general/201304/08/P201304080381.htm

International Social Services. (2012, September 12). Press release: Survey with the teachers of cross-border students. Retrieved from http://www.isshk.org/PublishWebSite/isshk/big5/contentPage38800.htm

Keung, A., \& Chan, M. (2005, September). Hong Kong school psychology student at the University of Florida. Communiqué, 34, 39-40.

Keung, Y.-C. \& Ho, C. S.-H. (2009). Transfer of reading-related cognitive skills in learning to read Chinese (L1) and English (L2) among Chinese elementary school children. Contemporary Educational Psychology, 34, 103-112.

Lam, S.-f., \& Lau. W.-S. (2008). Teachers' acceptance of peer coaching: Impact of collegiality and goal orientation. Journal of School Connection, 1, 3-24. 
Lam, S.-f., Cheng, R. W.-y., \& Choy, H. (2010). School culture and teacher motivation to implement project-based learning. Learning and Instruction, 20, 487-497.

Lam, S.-f., Chow-Yeung, K., Wong, B. P. H., Lau, K. K., \& Tse, S. I. (2013). Involving parents in paired reading with preschoolers: Results from a randomized controlled trial. Contemporary Educational Psychology, 38, 126-136.

Lam, S.-f., Jimerson, S., Kikas, E., Cefai, C., Veiga, F. H., Nelson, B., et al. (2012). Do girls and boys perceive themselves as equally engaged in school? The results of an international study from 12 countries. Journal of School Psychology, 50, 7794

Lam, S.-f., Wong, B., Leung, D., Ho, D., \& Au-Yeung, P. (2010). How parents perceive and feel about participation in community activities: The comparison between parents of preschoolers with and without autism spectrum disorders. Autism, 14, 359-377.

Lam, S.-f., Yim, P.-S., \& Ng, Y.-L. (2008). Is effort praise motivational? The role of beliefs in the effort-ability relationship. Contemporary Educational Psychology, 33, 694-710.

Lam, T. W. H., \& Chiu, C. Y. (2002). The motivational function of regulatory focus in creativity. Journal of Creative Behavior, 36, 138-150.

Legislative Assembly. (2013). Replies to initial written questions raised by Finance Committee members in examining the estimates of expenditure 2013-14: Question series number 4023. Retrieved from http://www.legco.gov.hk/yr12$\underline{\text { 13/english/fc/fc/w_q/lwb-ww-e.pdf }}$ 
Leung, C. M., \& Lam, S.-f. (2003). The effects of regulatory focus on teachers' classroom management strategies and emotional consequences. Contemporary Educational Psychology, 28, 114-125.

Liu, S. F. (2013, July 29). Minorities are facing many obstacles in education and employment. Singpao. Retrieved from http://www.singpao.com/xw/gat/201307/t20130729_449041.html

Mainland babies increased 57 times in 11 years. (2012, November 17). Apple Daily. Retrieved from http://hk.apple.nextmedia.com/news/art/20121117/18069121

Thomas, A., \& Grimes, J. (2008) (Eds.), Best practices in school psychology V. Bethesda: The National Association of School Psychologists

University of Hong Kong, Department of Psychology. (2012). Programme handbook of the M.Soc.Sc. in Educational Psychology (2012-14 ed.). Hong Kong: Author.

Wong, E. Y.-F., Ho, C. S.-H., Chung, K., Chan, D., Tsang, S.-M., \& Lee, S.-H. (2006). The Hong Kong Learning Behaviour Checklist for Preschool Children (Parent Version). Hong Kong: Hong Kong Specific Learning Difficulties Research Team. 